\title{
La Facultad de Derecho y Ciencias Sociales del Rosario en el recuerdo. Los inicios de la enseñanza jurídica universitaria en la ciudad
}

\author{
Pedro Boasso* \\ María Eugenia Libonati**
}

Fecha de Recepción: 08 de Agosto de 2020

Fecha de Aceptación: 03 de Octubre de 2020

DOI: https://doi.org/10.46553/RGES.56.2020.p.111-129

El 29 de diciembre de 2019 la Facultad de Derecho y Ciencias Sociales del Rosario cumplió su $60^{\circ}$ aniversario. Fundada a fines del año 1959 con el respaldo de monseñor Antonio Caggiano, y por iniciativa de algunos reconocidos abogados rosarinos -entre ellos, el destacado jurista y primer decano, Dr. Juan Casiello-, la Facultad se integró a la Universidad Católica Argentina, que había sido erigida un año antes en la ciudad de Buenos Aires. Sus cursos fueron inaugurados oficialmente en marzo de 1960, respondiendo de esta manera, a la vez, a la aspiración de los sectores católicos a contar con establecimientos propios de educación superior, y al reclamo de la sociedad local para que se creara una Facultad de Derecho en la ciudad.

En el marco del Proyecto de Investigación PRIJUR “Actores y proyectos culturales del catolicismo en Rosario. Juristas, saberes intelectuales y enseñanza universitaria, 1959-1972”, ${ }^{1}$ se ha dado inicio a un plan de entrevistas que persigue el objetivo de recuperar y preservar la memoria de quienes fueron docentes y alumnos durante los primeros años de vida de la institución.

A continuación, se presentan dos relatos testimoniales, recabados bajo la forma de cuestionario escrito.

\footnotetext{
* Instituto de Historia, Pontificia Universidad Católica Argentina. boassopedro@ gmail.com

** Instituto de Historia, Pontificia Universidad Católica Argentina. mariaeugenialibonati@gmail.com

${ }^{1}$ PRIJUR 2019-2021, aprobado por Res. Decanal N7218/19, Facultad de Derecho y Cs. Sociales del Rosario, PUCA. En ejecución.
} 
Entrevista al Dr. Luis Natalio Gardella, profesor retirado de la Facultad de Derecho y Ciencias Sociales del Rosario

El Dr. Luis Natalio Gardella Bértolo, de 96 años de edad, es abogado y ex profesor de la Facultad de Derecho y Ciencias Sociales del Rosario de la Pontificia Universidad Católica Argentina. Hijo de Luis Gardella y Rosa Bértolo, nació en el seno de una familia católica de la ciudad de Rosario, junto a sus cuatro hermanos (Lorenzo, María Isabel, María Rosa y Juan Carlos). En su escrito testimonial dedica un recuerdo a su tía paterna, Virginia -quien fue educadora y directora de la escuela Pestalozzi de Rosario-, que en la familia hizo las veces de segunda madre, y a sus primos, algunos dispersos por la mencionada ciudad, y otros en la de San Javier, al norte de la provincia de Santa Fe, de donde era oriunda su madre Rosa. Destaca el valor de la familia, y lamenta la crisis por la que atraviesa esta institución en la actualidad.

\section{Dr. Gardella, ¿qué puede contar de sus orígenes familiares?}

Todos los integrantes de mi familia (tanto el núcleo básico, como su extensión) fueron descendientes de inmigrantes de nacionalidad italiana, de 3era. generación en lo que a mí respecta, y consecuentemente no descendemos de los pueblos originarios de América, sino que como suele decirse "bajamos de los barcos" que nos trajeron de nuestra bella Europa, nuestra madre patria. Ah! Cuantas veces en los últimos tiempos comento con mis amigos y familiares "pero que tengo yo de americano si el nacer aquí es un hecho casual, mientras que genéticamente soy $100 \%$ italiano del norte (Génova por línea paterna y Friul por línea materna)", y dejo así abierta una cuestión para la polémica, siempre interesante y digna de ser correctamente resuelta.

\section{¿Qué formación académica recibió?}

Como mi padre era funcionario bancario (contador público egresado de nuestra facultad de Ciencias Económicas de Rosario), finalizó su carrera profesional como gerente de varias sucursales del Banco Hipotecario Nacional, entonces mis estudios primarios y secundarios transcurrieron en tres ciudades y provincias distintas. Ellas fueron: Paraná (Entre Ríos), Santa Rosa (La Pampa) y Rosario (Santa Fe). Debo aclarar que dichos estudios, tanto primarios 
como secundarios, fueron hechos en establecimientos modelo, como la Escuela Normal de Paraná, el Colegio Nacional de Santa Rosa y el Colegio Nacional Nro. 1 de nuestra ciudad. Esta última era una institución cuasi universitaria, sobre todo en los 4tos. y 5tos. Años, cuando nos graduábamos de bachilleres nacionales. El nivel académico se manifestaba excelente en todo, pero especialmente en la calidad de excepción del cuerpo docente. ¡Qué tiempos aquellos en que los alumnos esperábamos con ansias el comienzo de clases de historia, psicología, o de literatura! Pues disfrutábamos de ellas, formándonos intelectualmente y pasando momentos gratificantes. Resulta obvio informar que todos los establecimientos mencionados eran oficiales y laicos. Para ellos, mis fervientes aplausos, pro todo lo que me dieron en aquellos años fundamentales de mi vida, pero es bueno acotar que por entonces Argentina, en materia educacional ocupaba un lugar privilegiado en toda América. Puedo dejar constancia que tuve la suerte inmensa de que mi infancia y adolescencia transcurrieran en tiempos verdaderamente dichosos para mi querido país.

En lo que hace, ahora, a mis estudios universitarios, los cursé en la facultad de Ciencias Jurídicas y Sociales de la Universidad Nacional de La Plata, graduándome en junio de 1948 como reza en el diploma que tengo a mis espaldas. Para mi alma mater, como suele decirse, no cabe sino un cálido y emocionado recuerdo y gratitud. ¿Qué años maravillosos e imborrables pasé en sus claustros, en compañía amable de colegas futuros y admirando profesores todos de excepción, algunos juristas de renombre nacional e internacional! En la facultad platense de entonces el elenco docente era casi similar al de la UBA, es decir, la flor y la nata de las ciencias jurídicas del país. Lamentablemente, ante el tiempo transcurrido, la memoria es infiel, pero aún recuerdo el nombre ilustre de algunos de esos profesores que integraron mesas examinadoras de lujo o daban aulas verdaderamente magistrales, son por sus apellidos: González Calderón, Alsina, Argañaraz, Galli, Obarrio, Peco, Legón, Spota, Molinario, Acuña Anzorena, etc. Mis estudios universitarios fueron en calidad de estudiante libre -rendía los exámenes asistiendo unas semanas antes a las aulas para conocer a los profesores y el enfoque que los mismos daban a su materia- pero el último año debía hacerlo como regular, pues, a la aprobación de los exámenes se agregaba la tesis de investigación jurídica (en mi caso, trató sobre los derechos reales pretorianos, o sea, ya maduraba mi vocación civilista realista, indagando los orígenes romanos de esos maravillosos derechos subjetivos de hoy) y el curso práctico de adaptación profesional sobre el desarrollo procesal de un caso concreto. Ese último año en La Plata, viviendo en casa de pensión compartida con otros estudiantes (y entre ellos destaco al querido amigo y brillante profesor de nuestra facultad, el Dr. Juan José Casiello) fue absolutamente inolvidable. 
¿Cuál fue su motivación para seguir la carrera cursada?

Concluyo el tema referido a los estudios superiores para explicar muy someramente las motivaciones que me decidieron a seguir la carrera de Abogacía. Por entonces, y nos referimos a mediados del pasado siglo, donde no existía la multiplicidad de posibles destinos profesionales como sucede ahora, y por lo tanto la elección no resultaba demasiado trabajosa. Dada mi personalidad y condiciones intelectuales me pareció que lo mejor sin duda alguna era optar por la carrera de Abogacía. Pues siempre me interesaron los valores, y entre ellos la justicia como algo esencial para la vida en sociedad. Su ausencia, frente a la arbitrariedad, es insoportable para el hombre. Estimé y estimo ahora el valor justicia como el único instrumento eficaz contra los atropellos de los que la desconocen, sea el Estado o sean los particulares. En mi larga vida profesional, pude comprobar reiteradamente la verdad de mi idea instrumental de la justicia como arma eficiente contra los asaltos permanentes de la arbitrariedad. Y así ese concepto idealista, pero ajustado a la realidad, me encaminó a los estudios del derecho. No hubo nunca en dicha elección alguna intencionalidad materialista o lucrativa. No pesó para nada aquello de la salida laboral. No sé si en este aspecto estuve muy acertado. Pues si es cierto que tuve éxito en muchos juicios en tribunales, siempre fui un pésimo cobrador de honorarios. Es decir, nunca busqué en mi profesión el llamado éxito económico. Y reitero la pregunta: ¿estuve en ello acertado? Tal vez no, y sobre el caso tengo presente el título de un libro que nunca leí y que después de reflexionar largamente sobre él me pareció que expresaba una verdad clarísima. El título era y es "Hombre rico, hombre libre”. Otro tema este para la polémica, pero no debemos alejarnos del cuestionario. Ah! Y ahora sí, para concluir la respuesta, no debo dejar de mencionar la influencia que en mi decisión sobre los estudios de Abogacía tuvo mi querido hermano mayor el Dr. Lorenzo Gardella, vicedecano y profesor emérito de nuestra facultad, quien ya había dado ese paso hacia la ciencia del derecho en las opciones universitarias. Y claro, él fue siempre una invalorable guía en la toma de grandes decisiones.

¿Cuándo se produjo su ingreso como docente en la UCA y qué circunstancias rodearon ese ingreso?

Mi ingreso al cuerpo docente de la Facultad Católica de Derecho de Rosario ocurrió una tarde de marzo de 1964. Había sido designado Profesor adjunto en la cátedra de Derecho Civil IV, o 
sea la materia de los derechos reales, siendo el profesor titular el Dr. Alberto Molinas, conocido abogado, docente y brillante jurista de la ciudad de Santa Fe. Aún recuerdo ese importante momento de mi vida cuando el colega citado me recibió con los brazos abiertos en el amplio patio del Colegio La Salle, primera sede de nuestra Facultad, y luego de felicitarme me impartió algunas ideas sobre la práctica docente de la materia en la cual tenía tanta experiencia, todo afectuosamente y con modestia, pues el Dr. Molinas era una persona adornada de muchas virtudes, siendo la bondad, en grado superlativo, la número uno. Debo dejar constancia que fue, sin dudas, uno de los colegas que más influyó en mi actuación docente futura y tuve por su persona gran y justificada admiración. Una breve y dura anécdota da cuenta de su personalidad notable: en un examen de la materia en la Facultad de Derecho de la ciudad de Santa Fe, hacía ya algún tiempo, tuvo que aplazar a un alumno veterano que había fracasado en forma reiterada en pruebas anteriores. Al día siguiente fue informado de la trágica noticia de que el susodicho alumno se había suicidado. Ah! El golpe fue muy duro y el Dr. Molinas nunca más aplazó en sus exámenes universitarios, pensando seguramente que una mera evaluación intelectual no debía poner en juego el inestimable valor de la vida. En las mesas examinadoras que compartí con el colega así lo puede comprobar y más allá de los cuestionamientos que vienen a colación, lo comprendí y lo acepté como una manifestación de aquella bondad que siempre fue su señal distintiva.

¿Tuvo actuación como profesor en alguna otra institución además de la Facultad de Derecho y Cs. Sociales del Rosario? ¿En cuál o cuáles? ¿Cómo fue esa experiencia?

Mi actuación frente a las aulas (¡que tanto añoro!) comenzó unos años antes que en la Facultad Católica de Derecho. Ocurrió durante los tiempos en que el gobierno dispuso la obligatoriedad de la enseñanza de la religión católica en los niveles primarios y secundarios; y ante la falta de profesores en cantidad suficiente para atender tamaña demanda, la Iglesia Católica tuvo que acudir a sus fieles profesionales, especialmente aquellos que militaban en la Acción Católica Argentina, previas pruebas de capacitación. Y así fue que fui designado como profesor secundario de Religión Católica, desempeñándome durante los años de vigencia de dicha enseñanza en la materia de Enseñanza Bíblica correspondiente al 4to. año del bachillerato, actuando nada menos que en mi antiguo y querido Colegio Nacional $\mathrm{N}^{\circ} 1$ de Rosario. La materia no tenía vinculación con el Derecho, pero era sumamente interesante y la conocía plenamente a través de mi formación religiosa general y la específica en los Centros Universitarios de la ACA - uno de los cuales presidí durante muchos años-. Además, en mi 
tarea me empeñé más allá de lo confesional, en acentuar aquellos aspectos que hacen a la cultura general, en todos los libros bíblicos, pero especialmente en los cuatro Evangelios y sus complementos del Nuevo Testamento. Casi con sorpresa noté gran receptividad en el alumnado, lo que influyó para la continuidad de mis nuevas tareas docentes con aplomo y entusiasmo, y así pude comprobar que transitaba un camino vocacional que prácticamente nunca acabaría y sería esencial en mi vida.

¿Entre qué años fue docente de la Facultad de Derecho y Cs. Sociales del Rosario? ¿Cuál fue el motivo de la finalización de su carrera docente en la UCA?

Mi actuación docente en la Facultad Católica de Derecho, como profesor primero adjunto y luego titular en la cátedra de Derecho Civil IV, duró hasta las puertas del siglo actual (unos 35 años), y prosiguió luego cinco años más, actuando en extensión universitaria como profesor de lengua portuguesa con orientación jurídica. El motivo de la finalización de mi carrera docente en la UCA fue la aplicación de las normas reglamentarias sobre jubilación al cumplir la edad pertinente y lo hice con mucha pesadumbre pues sabía que me encontraba en plenas condiciones psicofísicas para continuar realizando en provecho propio y ajeno, tareas intelectuales, que como antes dijera, constituían una finalidad primordial en mi vida. Tanto me resistí a no abandonar la docencia, que con la colaboración de la ex alumna y ya doctora, Amalia Fiori, obtuvimos la aprobación para la realización del curso de Portugués ya citado y que felizmente alcanzó un éxito de excepción y es inolvidable en nuestra Facultad.

¿Qué materia o materias dictó en la Facultad de Derecho y Cs. Sociales, y a qué año del programa correspondian? ¿Qué otros docentes integraban la cátedra? ¿Recuerda los temas principales del programa, cuál era el enfoque de la cátedra, qué bibliografía se utilizaba?

En ese largo período (más de 40 años), fueron muchos los colegas que colaboraron en la cátedra, tanto de Derecho Civil como de lengua portuguesa con orientación jurídica. Pero luego de exigir a mi memoria, puedo seguidamente mencionarlos: los titulares fueron el ya mencionado Dr. Alberto Molinas, el Dr. Mario José Capón Filas, el Dr. Luis María Vives y el Dr. Nelson Cossari. Además y en trascendentes tareas, actuaron como adjunto el Dr. Juan Carlos Lapalma, las Dra Fiori, Tolosa y Mascanfroni y en años del comienzo la Dra. Felicia Zapata y el Dr. Pedro Etchevers. Pido disculpas si hay alguna lamentable omisión. Limitándome ahora a mi principal tarea docente, que fue el curso de derechos reales en la 
materia Derecho Civil, debo dejar constancia, que la enseñanza tenía una marcada orientación teórica y práctica. Siempre se procuraba relacionar las normas jurídicas con las situaciones concretas de la realidad, considerando casos judiciales específicos. La bibliografía no tenía límites tanto en lo nacional como en lo extranjero.

¿Podría contar su relación con otros profesores de la casa? ¿A quiénes recuerda del claustro docente de los primeros años, y cómo funcionaba ese claustro docente?

Quiero referirme a dos profesores, uno de la casa y otro de la Facultad hermana estatal, brillantes juristas en lo Civil y especialistas en derechos reales, con quienes tuve, felizmente, una larga y fecunda relación. Son los Dres. Capón Filas y Luis Andorno. Con ellos compartí aulas y exámenes, congresos y jornadas y sobre todo practiqué amistad imperecedera cuyos frutos aún perduran.

¿Cómo era la relación entre el cuerpo directivo y el claustro docente? ¿Qué instancias de encuentros habia: reuniones docentes, reuniones de camaradería, misas, actividades recreativas...?

Entre los recuerdos que estoy relatando, debo dejar constancia, por un lado, de lo excelente que fue la relación entre el claustro docente y el cuerpo directivo de la Facultad, a través de actos religiosos y de camaradería, y particularmente los claustros generales de profesores y las autoridades. A pesar de los muchos años transcurridos, nunca fui testigo de ningún choque o disonancia de magnitud en dicha relación.

¿Cómo estaba organizada la estructura administrativa de la Facultad? ¿Recuerda a alguien del personal administrativo de aquellos años?

En lo que hace a la estructura administrativa de la Facultad, muy simple en los primeros años, recuerdo una figura entrañable por su eficacia y bondad: Luis Tuccio, acompañado de su querida hija. Posteriormente, al crecer la Facultad, aumentaron también los problemas, pero el personal administrativo se desempeñó con eficacia y corrección, y como profesor recuerdo el trato afectuoso además de muy eficiente que nos dispensaran.

Y por fin, sobre el tema, algo que hoy nos sorprendería, jamás me enteré de huelgas u otras medidas de fuerza. Es que, ante la presencia de cualquier problema laboral o administrativo, 
las partes se reunían y dialogaban con mucho respeto y como pudimos comprobar siempre se consiguió una solución justa que armonizaba el conflicto. Nuestra Facultad, también en esa materia, fue un buen ejemplo entre los pares.

¿En qué sedes de la Facultad le tocó dar clases? ¿Tiene algún recuerdo particular de cada una de ellas?

Toda mi carrera docente en la UCA la desarrollé en las sucesivas sedes de la misma, o sea inicialmente en el querido y recordado Colegio La Salle, luego de un paso fugaz en el Colegio de las Hermanas Cabrini, nos instalamos en el grande $y$ hermoso edificio que fue originalmente de las Hermanas de la Santa Unión y pasó luego a serlo del Arzobispado de Rosario. Finalmente, en tiempos más recientes, en el edificio propio de la Avda. Pellegrini, verdadero ejemplo de campus universitario con el cual nuestra Facultad y sus hermanas consolidaron su posición a nivel nacional y más allá. Se comprende que la circunstancia apuntada es un verdadero privilegio para mi persona y conlleva un bagaje recordatorio riquísimo y gratificante, pero imposible ahora de resumirlo en algunas palabras. Sí, debo expresarles que todas esas sedes universitarias, donde di aulas y completé toda mi carrera docente están en plano de igualdad en mi memoria y cada vez que ocasionalmente paso frente a ellas es inefable la emoción que produce en mi corazón.

En relación con el alumnado, ¿cómo era el perfil de los alumnos de los primeros tiempos? ¿Por qué motivos piensa usted que los alumnos elegían a la UCA para realizar sus estudios universitarios?

En lo que hace al alumnado de la Facultad, sin duda parte esencial y razón de ser de la misma, dejo constancia que, más allá de casos excepcionales confirmatorios de la regla, fue de un comportamiento que merece ser destacado en todos los aspectos. Respecto de los posibles motivos de la elección de nuestra Facultad para la realización de sus estudios, creo que pesaron varios, pero especialmente el carácter confesional de la misma, ya que siendo cristianos deseamos formarnos profesionalmente en una Universidad que pertenece a la Iglesia Católica, y además la circunstancia de que en ella nunca penetraron exageradamente las ideologías políticas, que en su permanente y agitado debate contribuyen más a la división que al esclarecimiento positivo. Jamás se produjo un paro o huelga estudiantil, y ello creó una 
continuidad académica significativa para la previsibilidad de la tan deseada graduación, y por ello pesó y mucho en los momentos de elección.

¿Participó en alguna institución de la Iglesia Católica? (Parroquias - Acción Católica otras) ¿Se trató de una participación activa o de una simple adherencia? ¿Ocupó algún cargo directivo?

Como pertenecí a una familia católica en todo, desde adolescente formé parte de la Acción Católica y tuve en ella una muy activa participación integrando los distintos Centros hasta culminar en los de profesionales, presidiendo muchos años el Centro de Derecho Universitario de la ACA, que funcionaba en la sede episcopal de nuestra ciudad. Recuerdo que nuestro asesor fue el inolvidable Monseñor López y con él tuvimos reuniones y debates formativos en lo religioso y moral que dejaron huellas imborrables.

¿Recuerda el conflicto del gobierno peronista con la Iglesia Católica? ¿Qué actividad desempeñaba Ud. al momento de desatarse el mismo?

En cuanto al conflicto que fue durísimo choque entre el gobierno peronista y la Iglesia Católica debo decirles que actuaba como docente en mi Facultad y fui testigo de un desenlace que había comenzado auspicioso años atrás y que concluiría en un injustificado y brutal ataque contra la Iglesia, expulsando obispos e incendiando templos. Todavía recuerdo la presencia del Cardenal Caggiano en una ocasional visita a mi familia (el citado Cardenal y mi padre mantenían desde años una cordial amistad) en aquellos momentos dramáticos y sus palabras textuales fueron: “¡A estos ya no les creo ni el bendito!”, prosiguiendo - ante nuestro asombro- con el relato del peligroso e increíble andar en la techumbre de la Catedral de Buenos Aires para ponerse a salvo del incendio oprobioso. Ah! Cuántos hechos que forman parte de nuestra historia reciente, de contenido incalificable y que nunca deberían ser olvidados por las presentes generaciones para sacar conclusiones y actuar en consecuencia. La historia, verdad, es o debería ser maestra de la vida.

¿En qué ámbito o ámbitos se desempeñó en su vida profesional?

Mi vida profesional se desarrolló en tres ámbitos: ejercicio de la profesión como abogado litigante en los Tribunales Provinciales de mi ciudad, luego asesor jurídico y apoderado del 
Banco Hipotecario Nacional en la sucursal local, en la que ingresé como abogado ayudante y concluí jubilándome como abogado jefe del Área Letrada, y por fin la docencia de Derecho Civil en la Facultad Católica de Rosario, cumpliendo una tarea profesional que creo fue mi mayor y más gratificante vocación.

\section{¿Realizó publicaciones jurídicas o no jurídicas? ¿Las podría nombrar?}

En relación con las publicaciones jurídicas hechas durante mi actuación profesional docente, las mismas fueron hechas en las Memorias de los distintos Congresos y Jornadas Nacionales de Derecho Civil a los que asistí y participé, que fueron innúmeras. A título de ejemplo, cito la ponencia presentada en el IV Congreso de Derecho Civil de Córdoba que lleva por título "El Régimen de inscripción registral en la reforma (Art. 2505 del Cód. Civil y Ley 17801)" y que fuera publicada por la editorial de dicha Universidad mediterránea allá por 1969, y que tengo aquí a mi vista. Sobre el tema, deseo dejar constancia que por diversas circunstancias que no es el caso de puntualizar ahora, he quedado en deuda con mis queridos derechos reales respecto del tratamiento general o específico de largo aliento que mereciera ser volcado a uno o más libros, y ello es una falencia, sin duda, que no debo eludir.

\section{¿Hay alguna otra información o recuerdo que le parezca importante relatar?}

Observo ahora el cuestionario y lo veo respondido, al menos en lo fundamental, y para no demorar mi trabajo de respuesta al Instituto de Historia de la Facultad, su autor, lo doy por concluido expresando mi gratitud por acordarse de los antiguos profesores y darles la ocasión de evocar recuerdos y decir muchas cosas, no sé si importantes, pero seguramente útiles para la generación nueva que es protagonista en mi querido país.

Antes de poner punto final, me parece oportuno y si no importante, también pertinente, comentarles muy resumidamente, cuáles fueron las actividades -no laborales- que a lo largo de los años dieron plenitud a esa parte de la vida que suele llamarse ocio (descanso y esparcimiento) y que en mi caso fue de verdadera trascendencia. Las menciono muy apretadamente, con alguna acotación: la práctica de la amistad en todo momento, pues la considero una virtud. La lectura sin límites, causa principal de mi enriquecimiento espiritual. El amor a las bellas artes, para disfrutarlas y a veces practicarlas (en mi juventud hice estudios de dibujo y pintura y me relacioné con figuras notables de nuestra plástica rosarina. ¡Esa sí que fue importante!) Y mi eterna compañera, de la que fui y soy un auténtico fanático: la 
música, en todas sus formas, pero especialmente la clásica (mi padre, además de bancario fue un excelente pianista aficionado). El estudio libre pero bastante sistematizado de ciencias vinculadas a las jurídicas, como la filosofía y la psicología, llegando a formar una valiosa biblioteca. Y hablando de ocio positivo, no puedo dejar de mencionar la práctica deportiva, fuente de salud y amistad, y por fin (puede haber omisiones) la realización de viajes hacia todos los destinos posibles, aprovechando las ferias tribunalicias. Pero primeramente conocí mi terruño, en mi auto, solo o acompañado, transité desde el norte jujeño hasta Tierra del Fuego, y desde el Atlántico a la cordillera. Fue así que aprendí muchísimo de mi patria natal, relacionándome con cosas y personas y testimoniando grandezas notables y tristes falencias a resolver y claro, así aprendí a amarla, pero con sentido crítico, que hace el diagnóstico y busca la curación. Con mis viajes "internos", me di cuenta que se despertaba en mí un nuevo amor: esa parte maravillosa de nuestro territorio al sur del río Colorado, o sea la inefable Patagonia Argentina. Con el tiempo y los sucesivos viajes me convertí, geográfica e históricamente, en un cuasi especialista en el asunto y cuento con una bibliografía sumamente interesante y completa. En los últimos años, con la compañía de mi hermano Lorenzo, pude concretar importantes viajes al extranjero, comenzando con nuestro segundo hogar, o sea los países latino-europeos, y siguiendo luego con destinos al África, y Oceanía. Y no quiero olvidar mi viaje cuando era joven abogado, en una excursión colectiva a la Antártida y las principales bases nacionales. Y concluyamos ahora este enunciado de actividades al margen de lo profesional, pero que integran la vida de manera significativa: como siempre me atrajeron los idiomas, opté por el estudio de una lengua muy vecina del castellano, el portugués de Brasil, y así durante cinco años, en el Instituto Argentino-Brasileño de Rosario asistí a las clases de gramática primero, y luego culturales y de conversación, y así adquirí una segunda lengua que siempre me acompañó tanto en la literatura como en viajes y me permitió esa hermosa experiencia docente de portugués jurídico en nuestra Facultad, a la que antes hiciera mención. Ya terminadas mis respuestas al cuestionario, leo el texto y me doy cuenta que se trata de una compendiada biografía personal que requirió esfuerzo intelectual y de memoria, pero muy gratificante

al fin. Por ello les estoy muy agradecido y les digo de todo corazón, muchas, muchísimas gracias y hasta siempre.

Dr. Luis Natalio Gardella

Rosario, Junio 2020 


\section{Entrevista al Dr. Juan Manuel Villarruel, exalumno y profesor de la Facultad de Derecho y Ciencias Sociales del Rosario}

El Dr. Juan Manuel Villarruel nació en 1948, es abogado, licenciado en Filosofía y doctor en Ciencia Jurídicas y Sociales, y pertenece a una tradicional familia de la ciudad de Rosario. Todavía en la actualidad se desempeña como profesor de la Facultad de Derecho y Ciencias Sociales del Rosario, en la que ha desarrollado una larga trayectoria académica.

Dr. Villarruel, ¿Qué puede contar sobre sus estudios y la formación académica recibió?

Cursé mi formación primaria, entre los años 1954 y 1960, en las escuelas públicas: “Antonio Herrera", No 125, de la localidad de Funes, Provincia de Santa Fe, hasta mediados de cuarto grado; finalicé cuarto grado en la "Roque Sáenz Peña", N 102 , de Rosario, y quinto y sexto grados en la "General Manuel Belgrano", № 54, de Rosario.

Mi educación secundaria la realicé en el Colegio "La Salle" de Rosario, entre los años 1961 y 1965.

Estudié abogacía en la "Facultad Católica de Derecho y Ciencias Sociales del Rosario" (P.U.C.A.), entre los años 1966 y 1972.

Me recibí de licenciado en Filosofía en la "Facultad de Humanidades y Artes" de la Universidad Nacional de Rosario (U.N.R.), en el año 1985.

Obtuve el título de doctor en Ciencias Jurídicas y Sociales en la "Facultad de Derecho" de la Universidad Nacional del Litoral (U.N.L.), en el año 1989.

¿Cuál fue su motivación para seguir las carreras cursadas?

Mi vocación fue siempre doble, el permanente interrogarme y la búsqueda de justicia. Cursando quinto año del secundario fui de oyente a las clases de "Introducción al Derecho" de la Facultad de Derecho de la U.N.R., dictadas por el Dr. Werner Goldschmidt, quien me aconsejó estudiar primero Derecho, por tres razones, porque seguramente tendría familia y sería más fácil sustentarla como abogado que como licenciado en filosofía; segundo, porque era mejor tener base científica antes de estudiar filosofía y, tercero, porque "la vocación 
siempre se cumple" y, si mi vocación era la filosofía, coronaría los estudios de ésta, mientras que, si estudiaba primero filosofía, seguramente no estudiaría Derecho.

¿Qué profesores lo influenciaron más en sus estudios?

La Dra. María Antonia Leonfanti, por su fina percepción del fenómeno jurídico; el Dr. Lorenzo Antonio Gardella, en virtud de su vocación pedagógica y su acendrado iusnaturalismo, y el Dr. Werner Goldschmidt, dado su "sistema trialista", a través del cual podían "declinarse" todas las instituciones jurídicas, cual segunda lengua materna.

Usted estudió en la Facultad de Derecho y Ciencias Sociales del Rosario en sus primeros tiempos. ¿Le tocó dar el examen final de habilitación profesional ante el tribunal externo examinador? ¿Cómo fue esa experiencia?

Sí y lo recuerdo vívidamente, pues fuimos la última promoción que debió rendir el examen final de habilitación profesional, al inicio del año 1973. Fue una experiencia emocionante, pues lo vivíamos como un desafío hacia nuestra formación académica. Inolvidable es la figura de Lorenzo Antonio Gardella transformado de juez en curial, transmitiéndonos los caracteres propios de nuestra futura profesión, para salir airosos de tan singular prueba.

¿Cuándo se produjo su ingreso como docente en la UCA y qué circunstancias rodearon ese ingreso? ¿Recuerda haber participado o haber tenido conocimiento del conflicto conocido como "Laica o Libre", que posibilitó la creación de esta Universidad?

Mi vocación docente fue muy precoz pues, luego de cursar Derecho Civil I con la Dra. María Antonia Leonfanti, en el año 1966, me solicitó que me integrase a la cátedra como Ayudante Alumno, pomposo nombre para designar una actividad informal y ad honorem, con la cual me inicié en el año 1967 en la ayudantía del trabajo en comisiones de sus alumnos.

Apenas graduado, en el año 1973, me adscribí a la cátedra de Derecho Político, dirigida a la sazón por el Dr. Néstor Pedro Sagüés.

En el año lectivo 1974 también ingresé como adscripto a la cátedra de Filosofía del Derecho, cuya titularidad ejercía el Dr. Werner Goldschmidt.

Recuerdo el debate entre la educación "laica o libre", pero el mismo tuvo lugar varios años antes de mi ingreso a la vida universitaria y, por lo tanto, no me tuvo por partícipe. 
¿Tuvo actuación como profesor en alguna otra institución, además de en la Facultad de Derecho y Cs. Sociales del Rosario? ¿En cuál o cuáles? ¿Cómo fue esa experiencia?

En el año lectivo 1974 me incorporé a la cátedra de "Filosofía del Derecho" de la Facultad de Derecho de la Universidad Nacional de Rosario, a cargo de los Dres. Juan Carlos Gardella y Ariel Álvarez Gardiol, culminando mi carrera docente allí como Profesor Adjunto a cargo de la Titularidad de la Cátedra.

Asimismo, tuve el honor de compartir la cátedra de "Filosofía Política" con el Dr. Werner Goldschmidt en la otrora Escuela de Ciencia Política y Relaciones Internacionales de la Universidad Nacional de Rosario.

Ambas experiencias fueron maravillosas, tanto por las cualidades personales y docentes de quienes las conformaban, como por la libertad de cátedra que imperaba en ellas.

\section{¿Entre qué años fue docente de la Facultad de Derecho y Ciencias Sociales del Rosario?}

Mi docencia en la Facultad de Derecho y Ciencias Sociales del Rosario, como profesor, a través de las distintas categorías que jalonan el cursus honoris de la carrera docente, se extiende desde el año 1973 hasta el presente, desempeñándome actualmente como Profesor Titular Ordinario, incluso en las Facultades de Química e Ingeniería del Rosario y de Ciencias Económicas del Rosario, lo cual me convierte en el "Decano de los Docentes de Derecho" y único profesor simultáneo de las tres unidades académicas.

¿Qué materia o materias dictó en la Facultad de Derecho y Cs. Sociales, y a qué año del programa correspondian? ¿Qué otros docentes integraban la cátedra? ¿Recuerda los temas principales del programa, cuál era el enfoque de la cátedra, qué bibliografía se utilizaba?

Cuando ingresé a la cátedra de "Derecho Político", en el año 1973, la misma correspondía al segundo año del programa de la carrera de abogacía. Ejercía la titularidad el Dr. Néstor Pedro Sagüés y le secundaban, junto al suscripto, el Dr. Alejandro Cullerés y el Dr. Danilo Ademar Nencioni, exalumno éste infaustamente fallecido al poco tiempo.

El programa abarcaba desde teoría de la sociedad, pasando por la estructura del estado y culminando con los organismos internacionales.

El enfoque de la cátedra era realista, humanista y cristiano. 
La bibliografía utilizada eran los textos de Germán J. Bidart Campos, Santiago Fayt y Mario Justo López.

Al incorporarme a la cátedra de "Filosofía del Derecho", en el año 1974, se la impartía en el sexto año del programa de la carrera de abogacía. Su titular era el Dr. Werner Goldschmidt, colaborando con él el infrascripto.

La perspectiva de la cátedra se centraba en la "teoría trialista del mundo jurídico", elaborada por el titular de la cátedra, constituyendo la bibliografía troncal las obras de éste denominadas: "Introducción Filosófica al Derecho (El mundo jurídico y sus horizontes)” y "Ciencia de la Justicia (Dikelogía)".

¿Podría contar su relación con otros profesores de la casa? ¿A quiénes recuerda del claustro docente de los primeros años, y cómo funcionaba ese claustro docente?

Formaban parte del claustro docente sólo las Dras. María Antonia Leonfanti, Estrella Virgen Pereyra, Frida Pffirter de Armas y la primera egresada Beatriz Fernández de Abrach, el resto eran profesores varones.

¿Cómo era la relación entre el cuerpo directivo y el claustro docente? ¿Qué instancias de encuentros habia: reuniones docentes, reuniones de camaradería, misas, actividades recreativas...?

Era usual encontrarse con otros docentes en ocasión de las frecuentes misas que se oficiaban; en los partidos de fútbol donde participaban por igual profesores y alumnos, y compartiendo mesas de café, antes o después de cada clase, en la Cantina de Alcides.

¿Cómo estaba organizada la estructura administrativa de la Facultad? ¿Recuerda a alguien del personal administrativo de aquellos años?

Ineludible es el recuerdo del Secretario Administrativo, Sr. Tuccio, de cuerpo enjuto y un poquito encorvado, con sus grandes anteojos de marcos de pasta, secundado por su hija Coty. Posteriormente ingresó como Secretario Académico el Dr. Federico Lamas, a quien le sucedió el Dr. Caseta. 
¿En qué sedes de la Facultad le tocó dar clases? ¿Tiene algún recuerdo particular de cada una de ellas?

Comencé mi labor docente, en año 1973, en el primer piso del edificio del Colegio La Salle, sito en calle Mendoza 444 de Rosario; luego en el Colegio "Santa Unión de los Sagrados Corazones", a la sazón propiedad del Arzobispado de Rosario y, finalmente, en la sede actual de Avenida Pellegrini 3.314 de Rosario.

Cumplo en señalar que, antes de recibirme, durante un corto tiempo, se dictaron clases en el Colegio ubicado en calle Cochabamba al 700 de Rosario y que el examen de habilitación del año 1973 se rindió en la sede de la biblioteca radicada en calle Estanislao Zeballos al 700.

¿Recuerda haber participado en alguna ceremonia o acto especialmente significativo para la vida institucional o eclesial de la UCA?

Recuerdo haber participado en reuniones de análisis de los aportes brindados por el Concilio Vaticano II y, más recientemente, las palabras de homenaje, a cargo del suscripto, tanto en ocasión de la celebración del cincuentenario de la Facultad, cuanto de su declaración como Institución Benemérita de la Ciudad de Rosario por el Honorable Concejo Municipal de ésta.

¿Puede relatar algunas circunstancias políticas que sucedieron a lo largo de su carrera docente, y referir qué impacto tuvieron éstas en la trayectoria institucional de la UCA?

Como alumno, transité mi formación durante el golpe militar del 28/06/1966, día en que rendí mi primer parcial en la Facultad, el que fue de Introducción al Derecho, a cargo del Dr. Lorenzo Antonio Gardella. Luego, el 24/03/1976, ya como docente, vivencié el siguiente y último golpe de estado.

Más allá que algunos profesores ocuparon, a título personal, cargos públicos durante esas gestiones gubernamentales, no hubo un impacto institucional público y notorio en la vida de la Facultad.

En relación con el alumnado, ¿cómo era el perfil de los alumnos de los primeros tiempos? ¿Por qué motivos piensa usted que los alumnos elegían a la UCA para realizar sus estudios universitarios? 
El sistema de educación regular a ultranza, en horario vespertino, amén de un sistema de becas y préstamos de honor muy importante para su época, facilitaba el ingreso no sólo de quienes trabajaban, sino de aquellos que tenían una probada vocación, pero escasos recursos económicos.

El alumnado era muy formal, lo cual se trasuntaba incluso en la indumentaria, caracterizada por el saco y corbata en los hombres y tailleurs en las damas.

La formación humanista y cristiana preponderaba en la currícula, conformada por dos cursos de filosofía general; tres cursos de teología; cátedra de metodología en la investigación científica; moral profesional, etc., todo lo cual pesaba al momento de tomar una decisión acerca de a cuál universidad ingresar.

¿Cómo estaba integrada la Facultad, en esos primeros años, a la vida de la Iglesia argentina y a la sociedad?

Durante mi formación académica participábamos activamente en la Acción Católica Argentina (A.C.A.), en especial dentro de su rama denominada Juventud Estudiantil Católica (J.E.C.).

Corresponde también destacar los Cursos de Formación de Dirigentes, organizados por la Acción Católica Argentina en un inmueble de la calle Laprida al 800, en cuyo seno burilaba nuestro espíritu el contador Antonio Margariti.

¿Qué visión tiene de la Facultad hoy, y cómo la ve en relación con la sociedad?

Actualmente la Facultad descolla institucionalmente en su medio por su nivel científico, tanto en el sistema jurídico cuanto en las metodologías de investigación.

$\mathrm{Su}$ pedagogía es de avanzada y aplicada por profesores, tutores de grado y posgrado y gabinete pedagógico que, con total donaire, ha sabido sortear el súbito pasaje de la educación presencial a la virtual en esta época de Pandemia Covid 19.

Su integración a la vida social es ostensible, no sólo por las convocatorias que le formulan organismos gubernamentales o no, sino también por su inserción presencial en barriadas humildes a través de distintos consultorios jurídicos gratuitos y de grupos de pastoral social. 
¿Participó en alguna institución de la Iglesia Católica? (Parroquias - Acción Católica otras) ¿Se trató de una participación activa o de una simple adherencia? ¿Ocupó algún cargo directivo?

Como fue reseñado más arriba, formé parte de la Acción Católica Argentina (A.C.A.), en su rama de la Juventud Estudiantil Católica (J.C.E.), en la sede que funcionaba en la Parroquia María Auxiliadora, en calle Salta al 1600, hacia la década 1960-1970.

En el seno de la Facultad formé parte, de modo activo, pero no dirigencial, del Movimiento Social de Inspiración Cristiana (M.O.S.I.C.), creado en el año 1968, y del Instituto Social Cristiano de Estudios y Acción Política (I.S.C.E.A.P.), vinculados entre sí y en consonancia con el Mayo Francés.

¿Recuerda el conflicto del gobierno peronista con la Iglesia Católica? ¿Qué actividad desempeñaba Ud. al momento de desatarse el mismo?

Recuerdo relatos sobre dicho conflicto, pero al momento del golpe de estado del año 1955 tenía sólo 7 años de edad.

¿En qué ámbito o ámbitos se desempeñó en su vida profesional?

Desde el año 1973 hasta el presente ejerzo la profesión liberal.

Desde el advenimiento de la democracia, en el año 1983, hasta el mes de diciembre del año 1991 me desempeñé como Asesor de Bloque en la Cámara de Diputados de la Provincia de Santa Fe.

Desde el mes de diciembre del año 1991 hasta el mes de marzo del año 2017 trabajé en la Defensoría del Pueblo de la Provincia de Santa Fe, Sede Rosario, jubilándome como Sub Director de Relatoría y Análisis Normativo de la misma.

¿Ejerció actividad gremial o participó de algún colegio profesional?

Fui director del Colegio de Abogados de Rosario durante uno de los mandatos como presidente del Dr. Arturo Araujo. 
¿Ejerció alguna actividad politica durante su vida académica? ¿Se vinculó con algún gobierno o fue invitado a hacerlo?

Si bien no ejercí actividad política stricto sensu, fui convocado como personal político durante las gestiones de los gobiernos justicialistas de la Provincia de Santa Fe desde el año 1983 hasta el año 1995, para desempeñarme en los cargos susodichos de la Cámara de Diputados de la Provincia de Santa Fe y de la Defensoría del Pueblo de la Provincia de Santa $\mathrm{Fe}$, pasando luego a revestir como personal de planta permanente hasta mi jubilación en el mes de marzo del año 2017.

¿Realizó publicaciones jurídicas o no jurídicas? ¿Las podría nombrar?

He realizado múltiples publicaciones jurídicas, bajo forma de reseñas bibliográficas, artículos, ensayos y libros, en materias de filosofía del derecho, ciencia política, derecho laboral (procesal y de fondo) y medio ambiente, tanto provinciales, cuanto nacionales $\mathrm{e}$ internacionales.

¿Se encontró con lineamientos doctrinarios en pugna durante su carrera? ¿Se sintió identificado con alguno/s? ¿Cuáles fueron sus fuentes de inspiración a la hora de desarrollar sus tareas académicas?

Siempre el realismo iusnaturalista, el tridimensionalismo jurídico y la axiología general han sido mis brújulas académicas.

¿Hay alguna otra información o recuerdo que le parezca importante relatar?

Deseo destacar la fraternidad docente y el centrarse en el educando, cuales notas distintivas de nuestra comunidad académica.

Dr. Juan Manuel Villarruel

Rosario, Julio 2020 